\title{
Chemical composition and in vitro antioxidant activities of Thymelaea hirsuta L. essential oil from Tunisia
}

\author{
Adel Kadri ${ }^{1 \star}, Z_{\text {Zied Zarai }}{ }^{2}$, Ines Ben Chobba ${ }^{3}$, Néji Gharsallah ${ }^{3}$, Mohamed Damak ${ }^{1}$ and Ahmed \\ Békir $^{4}$ \\ ${ }^{1}$ Laboratoire de Chimie des Substances Naturelles, Faculté des Sciences de Sfax, B.P. 1171, 3000 Sfax, et and ISSAT \\ Gabès, Université de Gabès, Tunisia. \\ ${ }^{2}$ Laboratoire de Biochimie et de Génie Enzymatique des Lipases, ENIS, BPW, 1173 Sfax, university of Sfax, Tunisia. \\ ${ }^{3}$ Laboratoire de Biotechnologies Végétales Appliquées à l'Amélioration des Cultures, Faculté des Sciences de Sfax, \\ B.P. 1171, 3000 Sfax. Tunisia. \\ ${ }^{4}$ Département de Génie des procédés, ISET Sfax, Km 2,5 Rte de Mahdia, 3099 Sfax, University of Sfax, Tunisia.
}

\section{Accepted 17 March, 2011}

\begin{abstract}
This study was designed to examine for the first time, the chemical composition and in vitro antioxidant activities of the essential oil obtained from the aerial parts of Thymelaea hirsuta $L$. The essential oil was subjected to hydrodistillation and was analyzed by GC-FID and GC-MS. The chemical composition was dominated by the presence of hydrocarbon sesquiterpenes $(26.91 \%)$ with germacrene $D(12.98 \%)$ as the major component, while oxygenated sesquiterpenes and monoterpenes amounted to 13.82 and $13.29 \%$, respectively. The antioxidant properties of the studied essential oil were determined by three methods: diphenylpicrylhydrazyl (DPPH) assay, $\beta$-carotene bleaching assay and reducing power test and the results were compared to the reference BHT (butyl hydroxy toluene). In the three earlier mentioned assays, the essential oil demonstrated a potential antioxidant which may be considered as potent agent in food preservation and drug discovery.
\end{abstract}

Key words: Thymelaea hirsuta, essential oil, antioxidant activities.

\section{INTRODUCTION}

Thymelaea is a genus comprising about 30 species of evergreen shrubs under the flowering plant family Thymelaeaceae, which is native to the Canary Island, the Mediterranean region, north of central Europe and east of central Asia. In this report, Thymelaea hirsuta was focused on; a perennial, evergreen and dioecious shrub, which is native to North Africa. In the Republic of Tunisia, this plant is commonly known as "Methnane" and has been used traditionally as an antiseptic, for the treatment of hypertension and used as decoction in the treatment of diabetes (Ziyyat et al., 1997). However, it has been used in traditional medicine for its antimelanogenesis (Kawano

\footnotetext{
${ }^{\star}$ Corresponding author. E-mail: lukadel@yahoo.fr. Tel: +216-
} 93377588. et al., 2007), hypoglycaemic, antidiabetic (Djeridane et al., 2005) and antioxidant (El Amrani et al., 2009) properties.

Nowadays, there is increased interest in the use of plant essential oils and their components for the presservation of food since they have been known to exhibit biological activities, especially antimicrobial and antioxidant, and have also been the subject of study, particularly by the chemical, pharmaceutical and food industries, because of their potential use in food and biotechnology. Antioxidants are significant in the prevention of human illness and may function as free radical scavengers, complexes of pro-oxidant metals, reducing agents and quencher of singlet oxygen formation (Andlauer and Furst, 1998). Free radicals posses the ability to reduce the oxidative damage associated with many disease including neurodegenerative diseases, cancer, cardiovascular disease, cataracts and AIDS (Pietta et al., 
1998; Lee et al., 2000). The role of free radicals and active oxygen is becoming increasingly recognized in the pathogenesis of the many human diseases, including cancer, aging and atherosclerosis (Perry et al., 2000). The human body can be protected from these harmful compounds by enzymatic system, catalase, scavengers and antioxidants (Berger, 2006). Free radicals can also cause lipid peroxidation in foods which leads to their deterioration. There are some synthetic antioxidant compounds such as butylated hydroxytoluene (BHT) and butylated hydroxyanisole (BHA), which are associated with some side effects (Ito et al., 1983). These synthetic antioxidants have been questioned for their safety as carcinogenic. Therefore, research in the determination of natural sources of antioxidants and the antioxidant potential of plants is important. Plant essential oils as antioxidants were researched in detail with the view to investigate their protective role for highly unsaturated lipids (Deans et al. 1992) and biological activities (Vagionas et al., 2007; Wei and Shibamoto, 2007)

From what is known, there has not been elaborate published work on the chemical composition and the antioxidant activities of the essential oil of $T$. hirsuta. The present study was aimed to determine the chemical composition and the in vitro antioxidant activities of the aerial part of $T$. hirsuta essential oil, collected in the south-west of Tunisia.

\section{MATERIALS AND METHODS}

Plant materials (aerial parts) of $T$. hirsuta were collected at the flowering stage in

Sidi Aïch, Gafsa (mountainous region in south- west of Tunisia).

\section{Distillation method}

The dried aerial parts were ground prior to the operation and then $300 \mathrm{~g}$ of the ground rosemary were submitted for water distillation for $4 \mathrm{~h}$ using a Clevenger apparatus. The distilled essential oils were dried over anhydrous sodium sulfate, filtered and stored at $4^{\circ} \mathrm{C}$.

\section{GC/MS analysis conditions}

The essential oil was analyzed using an Agilent-Technologies $6890 \mathrm{~N}$ Network GC system equipped with a flame ionization detector and HP-5MS capillary column $(30 \mathrm{~m} \times 0.25 \mathrm{~mm}$, film thickness $0.25 \mu \mathrm{m}$; Agilent-Technologies, Little Falls, CA, USA). The injector and detector temperatures were set at 250 and $280^{\circ} \mathrm{C}$, respectively. The column temperature was programmed from 35 to $250^{\circ} \mathrm{C}$ at a rate of $5^{\circ} \mathrm{C} / \mathrm{min}$, with the lower and upper temperatures held for 3 and $10 \mathrm{~min}$, respectively. The flow rate of the carrier gas (helium) was $1.0 \mathrm{ml} / \mathrm{min}$. A sample of $1.0 \mu \mathrm{l}$ was injected, using split mode (split ratio, 1:100). All quantifications were carried out using a built-in data-handling programme provided by the manufacturer of the gas chromatograph. The composition was reported as a relative percentage of the total peak area. The identification of the essential oil constituents was based on a comparison of their retention times to n-alkanes, with published data and spectra of authentic compounds. The compounds were further identified and authenticated using their mass spectra which was compared to the Wiley version 7.0 library.

\section{Identification of the essential oil compounds}

The components of the essential oil were identified by comparing the mass spectra data with the spectra available from the Wiley 275 mass spectra libraries (software, D.03.00) and those in the literature (Adams, 2001), as well as by comparing the retention indices with literature data (Adams, 2001; Sibanda et al., 2004). Further identification confirmations were made referring to retention indices (RI) data generated from a series of known standards of n-alkanes mixture (C9-C28) (Kovàts, 1958) on the HP5 and HP-20M columns and to those previously reported in the literatures (Adams, 2001; Vagionas et al., 2007; Lopez-Lutz et al., 2008).

\section{Antioxidant activity}

\section{DPPH radical scavenging assay}

The ability of the oil essential of $T$. hirsuta to scavenge free radicals was assayed with the use of a synthetic free radical compound 1,1diphenyl-2-picrylhydrazyl (DPPH), according to the method employed by Bersuder et al. (1998). Briefly, a volume of $500 \mu \mathrm{l}$ of each sample was mixed with $500 \mu \mathrm{l}$ ethanol and $125 \mu \mathrm{l} 0.02 \%$ DPPH in $99.5 \%$ ethanol. The mixture was shaken vigorously and incubated in the dark. After $60 \mathrm{~min}$, the absorbance was measured at $517 \mathrm{~nm}$ using a spectrophotometer. The DPPH radicalscavenging activity was calculated as follows:

Radical-scavenging activity $=\left[\left(A_{\text {blank }}-A_{\text {sample }}\right) / A_{\text {blank }}\right] \times 100$

Where, $A_{\text {blank }}$ and $A_{\text {sample }}$ are the absorbance of the control (blank) and the sample, respectively. The $\mathrm{IC}_{50}$ value was defined as the amount of antioxidant necessary to inhibit DPPH radical formation by $50 \%$. The synthetic antioxidant reagent $\mathrm{BHT}$ was used as a positive control. The values were presented as the means of triplicate analysis.

\section{$\beta$-Carotene bleaching assay}

The antioxidant assay using the $\beta$-carotene bleaching was determined according to the protocol previously described (Koleva et al., 2002). $\beta$-Carotene $(0.5 \mathrm{mg})$ was dissolved in $1 \mathrm{ml}$ of chloroform and mixed with $25 \mu \mathrm{l}$ linoleic acid and $200 \mu \mathrm{l}$ Tween 40 . The chloroform was evaporated under vacuum at $40^{\circ} \mathrm{C}$, then, $100 \mathrm{ml}$ of distilled water was added and the resulting mixture was vigorously stirred. About $2.5 \mathrm{ml}$ of the obtained emulsion was transferred into different tubes containing $500 \mu \mathrm{l}$ of essential oil dissolved in ethanol at different final concentrations. The tubes were immediately incubated at $50^{\circ} \mathrm{C}$ for $120 \mathrm{~min}$ and the absorbance was measured at $470 \mathrm{~nm}$ before and after heat treatment. A control containing $0.5 \mathrm{ml}$ of ethanol instead of the sample solution was carried out in parallel. BHT was used as the positive control. The values were presented as the means of triplicate analysis.

\section{Reducing power antioxidant}

The ability of the oil to reduce iron (III) was determined according to the Yildirim et al. method (Yildirim et al., 2001) with some modifications. An aliquot of $500 \mu \mathrm{l}$ of each sample at different final concentrations was dissolved in ethanol and mixed with $1.25 \mathrm{ml}$ of $0.2 \mathrm{M}$ phosphate buffer $(\mathrm{pH} 6.6)$ and $1.25 \mathrm{ml}$ of $1 \%$ potassium 
ferracyanide.

The mixture was incubated for $30 \mathrm{~min}$ at $50^{\circ} \mathrm{C}$ and was followed by addition of $1.25 \mathrm{ml}$ of $10 \%(\mathrm{w} / \mathrm{v})$ trichloroacetic acid. The mixture was then centrifuged at $1500 \mathrm{~g}$ for $10 \mathrm{~min}$. Finally, $1.25 \mathrm{ml}$ of the supernatant solution was mixed with $1.25 \mathrm{ml}$ of distilled water and $250 \mu \mathrm{l}$ of $0.1 \%(\mathrm{w} / \mathrm{v})$ ferric chloride. After $10 \mathrm{~min}$, the absorbance was measured at $700 \mathrm{~nm}$. Increased absorbance of the reaction mixture indicated increased reducing power. The values were presented as the means of triplicate analysis.

\section{RESULTS AND DISCUSSION}

\section{Chemical composition}

The content of essential oil ( $\mathrm{g} / 100 \mathrm{~g}$ dry weight) was found to be $0.26 \%$. The percentage composition of the essential oil hydrodistillation from the $T$. hirsuta determined by GC-MS is presented in Table 1 in the order of their elution on the HP-5MS column. A total number of chemical constituents identified in $T$. hirsute essential oil were 29 compounds accounting for $99.98 \%$ of the total oil content. The main compounds were heptane $(28.34 \%)$, germacrene D (12.98\%), y-eudesmol (11.81\%) and citronellyl formate $(9.98 \%)$ followed by transcaryophyllene (3.25\%) cyclopentasiloxane decamethyl $(2.59 \%)$, $\delta$-cadinene $(2.55 \%)$ and $\beta$-bourbonene $(2.43 \%)$. The oil was characterized by a high amount of sesquiterpenes (40.73\%) including $26.91 \%$ of sesquiterpenes hydrocarbons and $13.82 \%$ of oxygenated sesquiterpenes. The amount of oxygenated monoterpenes was similar to the amount of oxygenated sesquiterpenes (13.26\%).

\section{Antioxidant activity}

It is known that free radicals are involved in the process of lipid peroxidation and play a crucial role in numerous chronic diseases such as cancer and coronary heart disease (Halliwell and Gutteridge, 2000). Thus, the ability to scavenge free radicals is an important antioxidant property in order to minimize oxidative cellular damage. For this, various in vitro methods have been developed to measure the efficiency of natural antioxidants either as pure compounds or as plant extracts and essential oil. These methods are popular due to their high speed and sensitivity. However, it is crucial to use more than one method to evaluate antioxidant capacity of plant materials because of the complex nature of phytochemicals (Salazar et al., 2008).

There is no data available on the antioxidant capacity of this essential oil. In this study, three complementary test systems, namely: DPPH free radicals scavenging, $\beta$ carotene bleaching test and reducing power assay were assessed.

\section{DPPH radical-scavenging activity}

The antioxidant activity of the volatile compounds from $T$. hirsuta essential oil was measured in terms of hydrogen donation or radical scavenging ability, using the stable radical, DPPH. The method is based on the reduction of alcoholic DPPH solutions in the presence of a hydrogen donating antioxidant. DPPH solutions show a strong absorption band at $517 \mathrm{~nm}$ appearing as a deep violet color. The absorption vanishes and the resulting decolourization is stoichiometric with respect to the degree of reduction. The remaining DPPH, measured after a certain time, corresponds inversely to the radical scavenging activity of the antioxidant. In this study, the results of the free radical scavenging activity of $T$. hirsuta and BHT assessed by DPPH assay are summarized in Table 2. The essential oil reduced the DPPH radical formation in a dose-dependent manner. The scavenging activities of the oil were $56.40 \pm 2.80,60.02 \pm 0.40,66.66$ $\pm 3.59 \%$ at 100,200 and $300 \mu \mathrm{g} / \mathrm{ml}$ of the oil concentrations, respectively. Comparison of these results with those expressed by BHT showed that $T$. hirsuta exhibited a slightly lower antioxidant effect than BHT $(66.66 \pm 3.59 \%$ and $82.24 \pm 2.02 \%$ at $300 \mu \mathrm{g} / \mathrm{ml}$, respectively). The amount of the essential oil needed for $50 \%$ inhibition of the free radical activity is expressed by $I_{50}$. Lower $I_{50}$ value indicates higher antioxidant activity. As shown in Table 2 , the $I \mathrm{C}_{50}$ value of the essential oil was equal to about half of that of the synthetic antioxidant BHT. The antioxidant activity found is attributed to the number of hydroxyl groups that are available to donate hydrogen atoms to the DPPH radical.

\section{$\beta$-Carotene bleaching method}

In this assay, antioxidant capacity was determined by measuring the inhibition of the volatile organic compounds and the conjugated diene hydroperoxides arising from linoleic acid oxidation. Hence, the free radical linoleic acid attacks the highly unsaturated $\beta$ carotene, and the presence of different antioxidants can hinder the extent of $\beta$-carotene bleaching by neutralizing the linoleate free radical and other free radicals formed in the system. There was rapid absorbance decrease in the samples without antioxidant, whereas in the presence of an antioxidant, the colour was retained for a long time. Table 3 shows the antioxidant activity of the essential oil and BHT as measured by the bleaching of the $\beta$ carotene-linoleate system. It was found that the radicalscavenging activity of $T$. hirsuta essential oil increased with increasing essential oil concentration. At $70 \mu \mathrm{g} / \mathrm{ml}$, the oil showed lower linoleic acid inhibition activity than BHT, which was almost $75 \%$ of the synthetic antioxidant $\mathrm{BHT}(58.30 \pm 0.67 \%$ vs. $77.50 \pm 1.00 \%)$. 
Table 1. Chemical composition, retention indices and percentage composition of the T. hirsute essential oil.

\begin{tabular}{|c|c|c|c|c|}
\hline $\mathbf{S} / \mathbf{N}$ & Compound & Retention indice (RI) & $\%$ & Identification \\
\hline 1 & 1-Heptene & 757 & 0.17 & MS, RI \\
\hline 2 & Heptane & 762 & 28.34 & MS, RI \\
\hline 3 & Hexamethylcyclotrisiloxane & 848 & 0.52 & MS, RI \\
\hline 4 & Iso menthone & 1205 & 0.48 & MS, RI \\
\hline 5 & Cyclohexaneethanol & 1275 & 0.33 & MS, RI \\
\hline 6 & $\beta$-citronellol & 1277 & 0.96 & MS, RI \\
\hline 7 & Citronellyl formate & 1318 & 9.98 & MS, RI \\
\hline 8 & Citrol & 1346 & 1.87 & MS, RI \\
\hline 9 & Dodecamethylcyclohexasiloxane & 1365 & 1.36 & MS, RI \\
\hline 10 & a-copaene & 1412 & 1.45 & $\mathrm{MS}, \mathrm{RI}$ \\
\hline 11 & $\beta$-Bourbonene & 1421 & 2.43 & MS, RI \\
\hline 12 & trans- $\beta$-caryophyllene & 1452 & 3.25 & $\mathrm{MS}, \mathrm{RI}$ \\
\hline 13 & a-Muurolene & 1463 & 0.47 & MS, RI \\
\hline 14 & $\alpha$ - Gurjunene & 1471 & 0.41 & $\mathrm{MS}, \mathrm{RI}$ \\
\hline 15 & Germacrene-D & 1479 & 12.98 & MS, RI \\
\hline 16 & $\alpha$-Humulene & 1483 & 0.95 & $\mathrm{MS}, \mathrm{RI}$ \\
\hline 17 & a-amorphene & 1489 & 1.49 & MS, RI \\
\hline 18 & $\delta$-selinene & 1499 & 0.31 & $\mathrm{MS}, \mathrm{RI}$ \\
\hline 19 & Aromadendrene & 1503 & 0.36 & $\mathrm{MS}, \mathrm{RI}$ \\
\hline 20 & $\begin{array}{l}\text { 5-Methyl-2-N-methylphenylamino-2- } \\
\text { thiazoline }\end{array}$ & 1532 & 0.43 & MS, RI \\
\hline 21 & ঠ-cadinene & 1543 & 2.55 & MS, RI \\
\hline 22 & a-agarofuran & 1563 & 0.26 & MS, RI \\
\hline 23 & Y-Eudesmol & 1625 & 11.81 & MS, RI \\
\hline 24 & Cyclopentasiloxane, decamethyl & 1659 & 2.59 & MS, RI \\
\hline 25 & Neryl acetate & 1695 & 0.56 & MS, RI \\
\hline 26 & linalyl acetate & 1697 & 0.19 & MS, RI \\
\hline 27 & Morphin silyliert & 1780 & 0.83 & MS, RI \\
\hline 28 & Tetradecamethyl-heptasiloxane & 1887 & 11.83 & $\mathrm{MS}, \mathrm{RI}$ \\
\hline 29 & Dodecamethyl-hexasiloxane & 1987 & 0.82 & MS, RI \\
\hline \multicolumn{2}{|c|}{ Total identification } & \multicolumn{3}{|c|}{99.98} \\
\hline \multicolumn{2}{|c|}{ Yield (g/100 g dry weight) } & \multicolumn{3}{|c|}{0.26} \\
\hline \multicolumn{2}{|c|}{ Hydrocarbon (\%) } & \multicolumn{3}{|c|}{28.51} \\
\hline \multicolumn{2}{|c|}{ Hydrocarbon monoterpenes (\%) } & \multicolumn{3}{|c|}{-} \\
\hline \multicolumn{2}{|c|}{ Oxygenated monoterpenes (\%) } & \multicolumn{3}{|c|}{13.29} \\
\hline \multicolumn{2}{|c|}{ Hydrocarbon sesquiterpenes (\%) } & \multicolumn{3}{|c|}{26.91} \\
\hline \multicolumn{2}{|c|}{ Oxygenated sesquiterpenes (\%) } & \multicolumn{3}{|c|}{13.82} \\
\hline
\end{tabular}

The components and their percentages are listed in the order of their elution on apolar column (HP-5).

As shown in Table 3 , the $\mathrm{IC}_{50}$ was determined and compared to the positive control BHT. The result showed that the essential oil of $T$. hirsuta exhibited significant potential for antioxidant activity estimated at about the half of BHT in the $\beta$-carotene/linoleic acid assay. This indicated that the essential oil protected the linoleic acid 
Table 2. Antioxidant activity of $T$. hirsuta essential oil and positive control (BHT) with the free radical DPPH scavenging assay.

\begin{tabular}{lcccc}
\hline \multirow{2}{*}{ Sample } & \multicolumn{3}{c}{ DPPH (\%) } & \multirow{2}{*}{ C $_{50}{ }^{\mathbf{a}}$} \\
\cline { 2 - 4 } & $\mathbf{1 0 0}^{\mathbf{a}}$ & $\mathbf{2 0 0}^{\mathbf{a}}$ & $\mathbf{3 0 0}^{\mathbf{a}}$ & \\
\hline Oil & $56.40 \pm 2.80$ & $60.02 \pm 0.40$ & $66.66 \pm 3.59$ & 80.75 \\
BHT & $83.00 \pm 1.54$ & $82.57 \pm 1.80$ & $82.24 \pm 2.02$ & 37.80 \\
\hline
\end{tabular}

${ }^{a}$ Concentration $(\mu \mathrm{g} / \mathrm{ml})$. Values represent average of triplicates \pm standard deviation.

Table 3. Antioxidant activity of $T$. hirsuta essential oil and positive control (BHT) with $\beta$-carotene bleaching method.

\begin{tabular}{lcccc}
\hline \multirow{2}{*}{ Sample } & \multicolumn{3}{c}{$\boldsymbol{\beta}$-Carotene linoleic acid (\%) } & \multirow{2}{*}{$\mathbf{I C}_{50}{ }^{\mathbf{a}}$} \\
\cline { 2 - 4 } & $\mathbf{1 0}^{\mathbf{a}}$ & $\mathbf{4 0}^{\mathbf{a}}$ & $\mathbf{7 0}^{\mathbf{a}}$ & \\
\hline Oil & $16.25 \pm 2.23$ & $47.24 \pm 2.00$ & $58.30 \pm 0.67$ & 20.30 \\
BHT & $27.00 \pm 3.00$ & $70.30 \pm 2.00$ & $77.50 \pm 1.00$ & 47.60 \\
\hline
\end{tabular}

${ }^{\mathrm{a} C}$ Concentration $(\mu \mathrm{g} / \mathrm{ml})$. Values represent average of triplicates \pm standard deviation.

Table 4. Antioxidant activity of $T$. hirsuta essential oil and positive control (BHT) with the reducing power test.

\begin{tabular}{lcccc}
\hline \multirow{2}{*}{ Sample } & \multicolumn{2}{c}{ Reducing power (absorbance at $\mathbf{7 0 0} \mathbf{~ n m}$ ) } & \multirow{2}{*}{$\mathbf{I C}_{\mathbf{5 0}}{ }^{\mathbf{a}}$} \\
\cline { 2 - 4 } & $\mathbf{1 0}^{\mathbf{a}}$ & $\mathbf{4 0}^{\mathbf{a}}$ & $\mathbf{7 0}^{\mathbf{a}}$ & \\
\hline Oil & $0.105 \pm 0.030$ & $0.392 \pm 0.030$ & $0.564 \pm 0.019$ & 58.50 \\
BHT & $0.390 \pm 0.022$ & $0.891 \pm 0.020$ & $1.051 \pm 0.010$ & 13.80 \\
\hline
\end{tabular}

${ }^{a}$ Concentration $(\mu \mathrm{g} / \mathrm{ml})$. Values represent average of triplicates \pm standard deviation.

against oxidation.

\section{Reducing power antioxidant}

Reducing power assay measures the electron-donating capacity of an antioxidant. The reducing properties are generally associated with the presence of reductones, which have been shown to exhibit antioxidant action by breaking the chain reactions and donating a hydrogen atom. Reductones are also reported to react with certain precursors of peroxide, thus preventing peroxide formation (Matsuchige et al., 1996). Being good electron donors, phenolic compounds show the reducing power and have ability to convert the ferric ion $\left(\mathrm{Fe}^{3+}\right)$ to ferrous ion $\left(\mathrm{Fe}^{2+}\right)$ by donating an electron (Shon et al., 2004). Increasing absorbance at $700 \mathrm{~nm}$ indicates an increase in reductive ability. The reducing power of the $T$. hirsuta essential oil and BHT were found to increase with increasing concentration, with a lower reductive potential of all oil concentrations when compared to the synthetic antioxidant (BHT). As can be seen from Table 4, the reducing power (absorbance at $700 \mathrm{~nm}$ ) value at the final concentration $(70 \mu \mathrm{g} / \mathrm{ml})$ were $0.564 \pm 0.019$, which is equal to about half of that of $\mathrm{BHT}(1.051 \pm 0.010)$. The $E_{50}$ value of $T$. hirsuta essential oil was $58.50 \mu \mathrm{g} / \mathrm{ml}$ which was about four times lower than that of BHT (13.80 $\mu \mathrm{g} / \mathrm{ml}$ ). The reducing power may be attributed to hydrogen donation from phenolic compounds (Shimada et al., 1992), which is also related to the presence of reductant agent, which can reduce the oxidized intermediates of lipid peroxidation processes and convert them to more stable products and consequently, terminate radical chain reactions.

By comparing the antioxidant activity measured by the three different methods and the relationships between the chemical composition and antioxidant activity, it is seen that $T$. hirsuta essential oil possesses a good capacity to scavenge free radicals and to prevent lipid peroxidation, which can be ascribed to the high content of hydroxylated compound. The ability to reduce Fe(III) may be attributed to the hydrogen donation from hydroxyl groups. Therefore, the antioxidant activities was attributed to the presence of oxygenated sesquiterpenes and monoter- 
penes that accounted for about $27 \%$ of the total $T$. hirsuta essential and to the possible synergy between various components.

\section{Conclusion}

The results of the study showed the first report of the chemical composition and in vitro antioxidant activity of the essential oil. The presence of hydroxylated groups such us phenolic and terpenoid compounds in the chemical composition may explain the antioxidant capacity and the protective effect of the investigated essential oil obtained with different methods of assessment. Complementary investigations are necessary to assess the effectiveness of this oil in food system and in the prevention and treatment of various human diseases.

\section{REFERENCES}

Adams RP (2001). Identification of essential oil components by gas chromatography /quadrupole mass spectroscopy. Allured Publishing Corporation, Carol Stream, Illinois.

Berger MM (2006). Nutritional manipulation of oxidative stress: review of the evidence. Nutrition Clinique et Métabolisme 20: 48-53.

Bersuder P, Hole M, Smith G (1998). Antioxidants from a heated histidineglucose model system I: Investigation of the antioxidant role of histidine and isolation of antioxidants by high performance liquid chromatography. J. Am. Oil Chemists' Soc. 75: 181-187.

Deans SG, Svoboda KP, Gundidza M, Brechany EY (1992). Essential oil profiles of several temperate and tropical aromatic plants: their antimicrobial and antioxidant activities. Acta Horticulture, 306: 229232.

Djeridane A, Yousfi M, Nadjemi B, Boutassouna D, Stocker P, Vidal N (2005). Antioxidant activity of some algerian medicinal plants extracts containing phenolic compounds. Food Chem. 97: 654-660.

El Amrani F, Rhallab A, Alaoui T, El Badaoui K, Chakir S (2009). Hypoglycaemi effect of $T$. hirsuta in normal and streptozotocininduced diabetic rats. J. Med. Plants Res. 3 (9): 625-629.

Halliwell B, Gutteridge JMC (2000). Free Radicals in Biology and Medicine. Oxford University Press, Oxford.

Ito N, Fukushima S, Hassegawa A, Shibata, M, Ogiso T (1983). Carcinogenecity of butylate hydroxyanisole in F344 rats. J. Natl. Cancer Inst. 70: 343-347.

Kawano M, Matsuyama K, Miyamae Y, Shinmoto H, Kchouk ME, Morio $\mathrm{T}$, Shigemori $\mathrm{H}$, Isoda $\mathrm{H}$ (2007). Antimelanogenesis effect of Tunisian herb Thymelaea hirsuta extract on B16 murine melanoma cells. Exp Dermatol. 16(12): 977-984.

Koleva I, van Beek TA, Linssen JPH, de Groot A, Evstatieva LN (2002). Screening of plant extracts for antioxidant activity: a comparative study on three testing methods. Phytochem. Anal. 13: 8-17.

Kovàts $E$ (1958). Characterization of organic compounds by gas chromatography. Part 1 Retention indices of aliphatic halides, alcohols, aldehydes and ketones. Helv. Chim. Acta 41: 19151932.
Lee KG, Mitchell AE, Shibamoto T (2000). Determination of antioxidant properties of aroma extracts from various beans. J. Agric. Food Chem. 48: 4817-4820.

Lopez-Lutz D, Alviano DS, Alviano CS, Kolodziejczyk PP (2008). Screening of chemical composition, antimicrobial and antioxidant activities of Artemisia essential oils. Phytochemistry, 69: 1732-1738.

Matsuchige K, Basnet, P, Kadota S, Namba T (1996). Potent free radical scavengingactivity of dicaffeoyl quinicacid derivatives from propolis. Traditional Medicines, 13(13): 217-228.

Perry RJ, Watson P, Hodges JR (2000). The nature and staging of attention dysfunction in early (minimal and mil) Alzheimer's disease: relationship to episodic and semantic memory impairment. Neuropsychologia, 38: 252-271.

Pietta P, Simonetti P, Mauri P (1998). Antioxidant activity of selected medicinal plants. J. Agric. Food Chem. 46: 4487-4490.

Salazar R, Pozos ME, Cordero P, Perez J, Salinas MC. Waksman N (2008). Determination of the antioxidant activity of plants from Northeast Mexico. Pharm. Biol. 46: 166-170.

Shimada K, Fujikawa K, Yahara K, Nakamura T (1992). Antioxidative properties of xanthan on the autoxidation of soyabean oil in cyclodextrin emulsion. J. Agric. Food. Chem. 40: 945-948.

Shon MY, Choi SD, Kahng GG, Nam SH, Sung NJ (2004). Antimutagenic, antioxidant and free radical scavenging activity of ethyl acetate extracts from white, yellow and red onions. Food Chem. Toxicol. 42: 659-666.

Vagionas K, Ngassapa O, Runyoro D, Graikou K, Gortzi O, Chinou I (2007). Chemical analysis of edible aromatic plants growing in Tanzania. Food Chem. 105: 1711-1717.

Wei A, Shibamoto T (2007). Antioxidant activities and volatile constituents of essential oils. J. Agric. Food Chem. 54: 1737-1742.

Yildirim A, Mavi A, Oktay M, Kara AA, Algur ÖF, Bilaloglu V (2000). Comparison of antioxidant and antimicrobial activities of tilia (Tilia argentea Desf Ex DC), sage (Salvia triloba L.) and black tea (Camellia sinensis) extracts. J. Agric. Food Chem. 48: 5030-5034.

Ziyyat A, Legssyer A, Mekhfi H, Dassouli A, Serhrouchni M, Benjelloun W (1997). Phytotherapy of hypertension and diabetes in oriental Morocco. J. Ethnopharmacol. 58: 45-54. 